\title{
ANÁLISE GENÉTICA EM GENÓTIPOS DE MANGA ROSA VIA REML/BLUP
}

Maria Clideana Cabral Maia ${ }^{1}$, Marcos Deon Vilela de Resende ${ }^{2}$, Luís Cláudio de Oliveira $^{3}$, Lúcio Flavo Lopes Vasconcelos ${ }^{4}$, João Francisco Pinheiro Lima Neto ${ }^{5}$

Resumo: O objetivo desse trabalho foi realizar uma seleção precoce com base nas características agro-industriais dos genótipos que compõem a população base do programa de melhoramento da manga rosa da Embrapa Meio-Norte. Foi utilizado o procedimento padrão de avaliação genotípica REML/BLUP (máxima verossimilhança residual ou restrita/melhor predição linear não viciada) na estimação de componentes de variância e a predição dos valores genotípicos. As estimativas dos coeficientes de repetibilidade foram altos e medianos expressando grande estabilidade para as variáveis em diferentes frutos. As estimativas de repetibilidade individual variaram de $43 \%$ a 77\%. Para obtenção de um coeficiente de determinação do valor genotípico de $90 \%$ são necessárias 10, 5 e 3 medições, para os caracteres com repetibilidade individuais de $43 \%, 65 \%$ e $77 \%$, respectivamente. As variáveis massa do fruto e massa da polpa apresentaram altas correlações genéticas com as variáveis comprimento e diâmetro maior e menor do fruto. Estas podem ser tomadas para seleção indireta das primeiras que são de mensuração mais difícil. Ocorreu uma alteração no ordenamento dos genótipos entre as variáveis quanto aos ganhos genéticos como reflexo da correlação genotípica de baixa a média magnitude exceção feita para as variáveis massa do fruto e massa da polpa e entre sólidos solúveis totais ( ${ }^{B}$ rix) e pH.

PALAVRAS CHAVE: Mangifera indica L, ganhos genéticos, modelos mistos.

\footnotetext{
${ }^{1}$ Engenheira Agrônoma, Dra. Genética e Melhoramento de Plantas, Embrapa Meio Norte - PI, clideana.maia@embrapa.br.

${ }^{2}$ Engenheiro Agrônomo, Dr. Genética e Melhoramento de Plantas, Universidade Federal de Viçosa/Embrapa Florestas - MG/PR, marcos.deon@gmail.com.

${ }^{3}$ Engenheiro Florestal, MS, Agro-silvicultura, Embrapa Acre - AC, luis.oliveira@embrapa .br

${ }^{4}$ Engenheiro Agrônomo, Dr. Fitotecnia, Embrapa Meio Norte - PI, lucio.vasconcelos@embrapa.br.

${ }^{5}$ Engenheiro Agrônomo, Dr. Genética e Melhoramento de Plantas, Embrapa Semi-Árido - PE, pinheiro.neto@embrapa.br.
}

Revista Agrotecnologia, Anápolis, v. 5, n. 1, p. 01 - 16, 2014 


\title{
GENETIC ANALYSIS AT GENOTYPES OF MANGO ROSA USING REML/BLUP
}

\begin{abstract}
The objective of this paper was to make an early selection based on agroindustrial characteristics of the genotypes from the base population of the mango's breeding program of the Embrapa Meio-Norte. We used the standard procedure to genotypic assessing REML/BLUP (restrict maximum likelihood/best linear unbiased prediction) to estimate the components of variance and to predict the genotypic values. The estimates of repeatability coefficients were high expressing great stability for the variables in different fruits. The individual estimates of repeatability ranged between $43 \%$ and $77 \%$. To obtain a coefficient of determination of the genotypic value the $90 \%$ is necessary 10, 5 and 3 measurements to characters with individual repeatability the $43 \%, 65 \%$ and $77 \%$, respectively. The fruit mass and pulp mass presented high genetic correlation with length and diameter (minor and larger) of the fruit. Therefore they can be used to indirect selection because your assessing is cheap in relation the firsts. Changes have occurred in the ranking of genotypes between variables as a result of the low genetic correlations except for the variables fruit mass and pulp mass and between soluble solids ( Brix) and $\mathrm{pH}$.
\end{abstract}

KEYWORDS: Mangífera indica L, genetic gains, mixed models.

\section{INTRODUÇÃO}

A grande concentração da produção e exportação brasileira de manga refere-se a cultivar 'Tommy Atkins' que, apesar de sua excelente coloração da casca e boa resposta à indução floral , apresenta baixa qualidade quanto ao sabor (sólidos solúveis totais - Brix $<17^{\circ}$ ) e à cor de polpa amarelo-esmaecida. Além disso, essa variedade apresenta problemas de suscetibilidade à malformação floral, à mosca-das-frutas, ao colapso interno de polpa e à alta exsudação de látex que afetam a quantidade e a qualidade do fruto no mercado consumidor (PINTO et al., 2011). Neste sentido, devido à exploração comercial, há uma iminente 
probabilidade de substituição de variedades locais (Landraces) por variedades comerciais promovendo progressivamente perda de material genético como a manga rosa que passou por processo evolutivo no sentido de atingir picos mais elevados de adaptabilidade às condições agroecológicas da região Meio-Norte do Brasil.

Os programas de melhoramento genético da mangueira visam atender, simultaneamente, os produtores que anseiam por variedades que apresentem maior produtividade e estabilidade de produção, sejam de fácil manejo nos tratos culturais e adaptadas às condições climáticas adversas da região para onde tiverem sido desenvolvidas, os distribuidores que desejam variedades que resistam ao manuseio e ao transporte e, finalmente, os consumidores que procuram manga de melhor qualidade, primeiro atraídos pela cor do fruto e depois pelo sabor. Para que as chances aumentem na difícil tarefa de desenvolver nova cultivar com a maioria das características desejáveis, é necessário que o melhorista tenha à sua disposição uma aceitável variabilidade genética, excelentes conhecimentos sobre a biologia floral, sobre o modo de reprodução e a herdabilidade dos caracteres desejados. Portanto, novas cultivares somente serão aceitas se apresentarem, para os diversos segmentos da cadeia produtiva, alguma(s) vantagem (ns) em relação às já existentes no mercado (PINTO et al., 2011).

Em se tratando de espécie perene, o melhoramento genético requer a realização de medidas repetidas em cada indivíduo, o que representa uma dificuldade intrínseca por envolver tempo geralmente elevado para recomendação de uma cultivar superior. A seleção precoce constitui, assim, uma alternativa mais ágil para a formação de populações-base (MAIA et al., 2011).

Devido a sobreposição de gerações e ao desbalanceamento (mortalidade ao longo do tempo) associados aos dados de caracteres quantitativos em espécies perenes, procedimentos mais precisos de predição de valores genéticos e estimação de componentes de variância foram desenvolvidos, tais como a melhor predição linear não viciada (BLUP) e a estimação por máxima verossimilhança restrita (REML). Estes procedimentos apresentam várias propriedades teóricas e práticas 
desejáveis, mas ainda são muito pouco utilizados no melhoramento de plantas frutíferas (RESENDE; DIAS, 2000). Não existem na literatura estudos genéticos para a manga rosa utilizando o procedimento REML/BLUP.

O objetivo desse estudo foi obter informações técnicas para a realização de uma seleção precoce, na cultura da mangueira, com base nas características agroindustriais, dos genótipos que compõem a população base do programa de melhoramento da variedade rosa da Embrapa Meio-Norte.

\section{MATERIAL E MÉTODOS}

O material genético foi obtido através de polinização aberta entre matrizes de manga rosa e variedades comerciais. A manga rosa é adaptada às condições ecológicas da região meionorte sendo a variedade local mais amplamente aceita pelos consumidores do mercado regional devido, especialmente, a cor atrativa, ao sabor, ao cheiro característico do fruto e a baixa ocorrência de colapso interno. Os genitores masculinos foram às seguintes cultivares comerciais e suas principais características:
- Irwin - árvore pequena, de copa aberta, com fruto médio de 340 a $450 \mathrm{~g}$, oval e alongado, de cor laranja-amarelada com laivos vermelhos profundos, polpa amarela, suave de pouca fibra e com semente monoembriônica.

- Keitt - árvore de copa espraiada que apresenta produção elevada e maturação dos frutos tardia, fruto grande de 550 a $740 \mathrm{~g}$, oval, verde-amarelado, corado de vermelho-róseo, fibra somente em volta da semente, semente monoembriônica, e relação polpa/fruto em torno de 0.7 .

- Palmer - árvore de copa aberta, com frutos vermelhos escuro, de polpa amarelada, firme, com pouca ou nenhuma fibra, relação polpa/fruto de 0.7 , teor médio de fibra e casca fina e sementes monoembriônicas.

- Tommy Atkins - árvore cheia e densa, com fruto de tamanho médio (450g), oval, de casca espessa, laranja-amarelo coberto com vermelho e púrpura intenso, firme, suculento, teor de fibra médio e teor de sólidos solúveis médio (179).

- Amrapali - árvore de porte anão, precoce, de produção regular, fruto de tamanho médio, doce e sem fibras.

- Sensation - árvore de copa grande, aberta, produtiva, fruta avermelhada, 
atrativa, boa qualidade da polpa e sem fibras.

Com base na autofecundação aparente se estabeleceu um esquema de cruzamentos abertos para obtenção da população segregante onde genótipos de manga rosa (parental feminino) selecionados para características agroindustriais foram circunvizinhados por variedades comerciais (parentais masculinos) onde se espera uma maior probabilidade de ocorrer cruzamentos entre as plantas vizinhas. Análises moleculares serão requeridas para determinar os genitores das progênies.

As variáveis agro-industriais analisadas nos genótipos descendentes, avaliados em experimento no delineamento inteiramente casualizado com uma planta por parcela, foram: massa do fruto $(\mathrm{g})$, comprimento do fruto - CF (mm), diâmetro do fruto - DF (mm), massa da casca (g), massa da semente (g), massa da polpa (g), porcentagem de polpa (\%), firmeza da polpa, teor de sólidos solúveis totais
(̊Brix), relação sólidos solúveis totais/Acidez e pH. O experimento foi implantado em um só local em Teresina - Piauí. As avaliações foram realizadas em 5 frutos de cada planta, caracterizando um experimento de medidas repetidas.

O modelo estatístico utilizado foi o que segue:

$y=X b+Z g+e$, em que:

$y, b, g, e$ : vetores de dados observados, de efeitos de medições ( efeito fixo), de valores genotípicos (aleatórios) e de erros aleatórios, respectivamente.

$X$ e $\mathrm{Z}$ : matrizes de incidência para $\mathrm{b}$ e $\mathrm{g}$ , respectivamente.

Esse modelo de repetibilidade equivale à estrutura de covariância denominada de simetria composta, a qual é adequada ao presente caso. O modelo é adequado tanto para o caso de medidas repetidas no tempo quanto para medidas repetidas no espaço.

\section{Equações de Modelo Misto:}

$\left[\begin{array}{cc}X X & X^{\prime} Z \\ Z^{\prime} X & Z^{\prime} Z+I\left(\sigma_{e}^{2} / \sigma_{g}^{2}\right)\end{array}\right]\left[\begin{array}{l}\hat{b} \\ \hat{g}\end{array}\right]=\left[\begin{array}{c}X^{\prime} y \\ Z^{\prime} y\end{array}\right]$, onde I é uma matriz identidade; $\sigma_{g}^{2}$ é a variância genotípica e $\sigma_{e}^{2}$ a variância residual. 


\section{Estimador REML}

Segundo o modelo apresentado e o algoritmo EM, os estimadores para obtenção de $\sigma_{g}^{2}$ e $\sigma_{e}^{2}$ são:

$\hat{\sigma}_{e}^{2}=\left[y^{\prime} y-\hat{b}^{\prime} X^{\prime} y-\hat{g}^{\prime} Z^{\prime} y\right] /[N-r(X)] ; \mathrm{e}$

$\hat{\sigma}_{g}^{2}=\left[\hat{g}^{\prime} \hat{g}+\sigma_{e}^{2} \operatorname{tr} C^{22}\right] / N_{g}$, em que:

$N g$ : número de elementos aleatórios (indivíduos);

I: matriz identidade;

$t r$ : operador traço matricial, dado pela soma dos elementos da diagonal da matriz;

$N$ : número total de dados;

$r(X)$ : posto ou número de colunas linearmente independentes de $\mathrm{X}$; e

$C 22$ é da forma $\left[\begin{array}{ll}C^{11} & C^{12} \\ C^{21} & C^{22}\end{array}\right]=\left[\begin{array}{cc}X^{\prime} X & X^{\prime} Z \\ Z^{\prime} X & Z^{\prime} Z+A^{-1}\left(\sigma_{e}^{2} / \sigma_{g}^{2}\right)\end{array}\right]^{-1}$.

As soluções para as equações de modelo misto devem ser obtidas por métodos iterativos de resolução de sistemas de equações lineares, tais como o método de Gauss Seidel. A solução direta via inversão da matriz dos coeficientes é impossível na prática.

\section{RESULTADOS E DISCUSSÃO}

$\mathrm{Na}$ Tabela 1 estão representados os resultados referentes às estimativas de componentes de variância (REML individual) para as variáveis: massa do fruto, massa da casca, massa da semente, massa da polpa, porcentagem de polpa, firmeza do fruto, sólidos
A estimação dos parâmetros genéticos e predição dos ganhos genéticos foram realizadas por meio de software SELEGEN-REML/BLUP desenvolvido pelo Centro Nacional de Pesquisa de Florestas da Embrapa Empresa Brasileira de Pesquisa Agropecuária. solúveis totais ( ${ }^{\circ}$ Brix), relação sólidos solúveis totais $\left({ }^{\circ} \mathrm{Brix}\right) / \mathrm{Acidez} \mathrm{e} \mathrm{pH}$.

No contexto da avaliação genotípica, o parâmetro estatístico mais importante é a acurácia seletiva (Acm). Esse parâmetro refere-se à correlação entre o valor genotípico verdadeiro do material genético e aquele estimado ou predito a partir das informações dos 
experimentos de campo. A acurácia é tanto mais alta quanto menores forem os desvios absolutos entre os valores genéticos paramétricos ou verdadeiros e os valores genéticos estimados ou preditos. Altas acurácias foram observadas para todas as variáveis consideradas no estudo, onde se infere boa qualidade da avaliação genotípica, indicando existência de variância genética entre os genótipos avaliados. Exceção feita ao atributo porcentagem de polpa $(0,654)$, que apresentou acurácia apenas mediana. Conforme Cargnelutti-Filho e Storck (2009), em geral ensaios com maior acurácia seletiva, são aqueles com menor variância residual e maior variância genética. Quanto maior o número $\mathrm{m}$ de medições em cada planta, maiores são as acurácias das predições e, portanto, mais precisas são as inferências. A acurácia é uma medida que está associada à precisão na seleção, sendo o principal componente do progresso genético que se pode alterar para maximizar o ganho genético.

As estimativas de repetibilidade individual variaram de $43 \%$ a $77 \%$ (Tabela 1), valores esses classificados como valores de moderada (entre $40 \%$ e $60 \%$ ) a alta (maior que 60\%) magnitudes. Esses valores sugerem que existe variância genética a ser explorada na seleção entre os genótipos, indicando que a população pode ser considerada apropriada para o programa de melhoramento genético através dessa estimativa de considerável controle genético.

Estimativas da herdabilidade individual no sentido restrito para vários caracteres em manga foram apresentadas por Hardner et al. (2012) na Austrália. As magnitudes variaram de $46 \%$ a $94 \%$, revelando um controle genético moderado a alto, concordando com os resultados obtidos no presente trabalho. Os autores também usaram a metodologia REML/BLUP, a qual mostrou-se muito efetiva no melhoramento da mangueira. Outros artigos relatam também controle genético alto para caracteres produtivos em manga (LAVI et al., 1989; 1998). 
MAIA, M. C. C. et al.

Tabela 1. Estimativas dos componentes de variância (REML individual) para as variáveis: massa do fruto, massa da casca, massa da semente, massa da polpa, \% de polpa, firmeza do fruto, sólidos solúveis totais ( ${ }^{\circ}$ Brix), relação: sólidos solúveis totais ( ${ }^{\circ}$ Brix) / Acidez e pH, de genótipos de manga rosa.

Componentes de Variância (REML Individual)

\begin{tabular}{|c|c|c|c|c|c|c|c|c|c|}
\hline & $\begin{array}{l}\text { Massa do } \\
\text { Fruto }\end{array}$ & $\begin{array}{l}\text { Massa da } \\
\text { Casca }\end{array}$ & $\begin{array}{l}\text { Massa } \\
\text { Semente }\end{array}$ & Massa Polpa & $\%$ Polpa & $\begin{array}{l}\text { Firmeza do } \\
\text { fruto }\end{array}$ & $\begin{array}{l}\text { sólidos } \\
\text { solúveis totais }\end{array}$ & $\begin{array}{l}\text { sólidos } \\
\text { solúveis totais } \\
\text { /Acidez }\end{array}$ & $\mathrm{pH}$ \\
\hline $\mathrm{Vg}$ & 18261,9585 & 364,3810 & 169,0116 & 10963,0409 & 11,1688 & 7,6746 & 8,5688 & 482,0795 & 0,1448 \\
\hline Vet & 5278,0107 & 130,8879 & 99,5586 & 5282,4597 & 14,9257 & 2,2925 & 5,0853 & 140,1573 & 0,0772 \\
\hline Vf & 23539,9692 & 495,2690 & 268,5701 & 16245,5006 & 26,0944 & 9,9671 & 13,6542 & 622,2367 & 0,2220 \\
\hline r & $0,775785+/-$ & $0,735724+/-$ & $0,629301+/-$ & $0,674836+/-$ & $0,428013+/-$ & $0,769992+/-$ & $0,627562+/-$ & $0,774753+/-$ & $0,652132+/-$ \\
\hline & 0,3714 & 0,3617 & 0,3345 & 0,3464 & 0,2758 & 0,3700 & 0,3543 & 0,3936 & 0,3657 \\
\hline Ac & 0,880787 & 0,857743 & 0,793285 & 0,821484 & 0,654227 & 0,877492 & 0,792188 & 0,880200 & 0,807547 \\
\hline Média & 350,8686 & 47,7271 & 40,2260 & 261,6501 & 73,8449 & 6,3898 & 16,0867 & 41,1747 & 4,1653 \\
\hline
\end{tabular}

Vg: variância genotípica entre plantas (genotípica + ambiental permanente de uma colheita para outra). Vet: variância de ambiente temporário. Vf: variância fenotípica individual. r: repetibilidade individual. Ac: acurácia da seleção baseada em uma colheita ou medida repetida e média geral do experimento.

Revista Agrotecnologia, Anápolis, v. 5, n. 1, p. 01 - 16, 2014 
Para obtenção de um coeficiente de determinação do valor genotípico de 90\% são necessárias 10, 5 e 3 medições, para os caracteres com repetibilidade individuais de 43\%, $65 \%$ e $77 \%$, respectivamente.

A variância genética observada na população estudada incrementa a possibilidade de obtenção de ganhos genéticos sendo reflexo da utilização nos cruzamentos de parentais geneticamente divergentes e indivíduos que apresentam superioridade per se para as características alvo, condição que favorece o surgimento de segregrantes transgressivos através de boa complementariedade gênica. Para Brown et al. (2009) o melhoramento de manga pode ser bem sucedido como resultado de alto nível de variabilidade genética, principalmente, nos casos em que os materiais genéticos selecionados são propagados via reprodução vegetativa.

Com o aumento do número de avaliações em cada planta, ocorre um aumento da herdabilidade no âmbito de médias de indivíduo e também da acurácia seletiva (ALVES; RESENDE, 2008). Em concordância com esses autores, Brown et al. (2009) encontraram maiores herdabilidades quando um maior número de frutos foi analisado por cada indivíduo. Para espécies com possibilidade de propagação vegetativa, a repetibilidade ao invés da herdabilidade no sentido amplo pode ser considerada um parâmetro adequado para inferir sobre o controle genético dos caracteres.

Valores altos a moderados de repetibilidade foram encontrados para as variáveis incluídas no estudo. As estimativas dos coeficientes de repetibilidade altos e medianos expressaram maior estabilidade para as variáveis consideradas no estudo e através do seu estudo é possível estimar o número de medições necessárias para predizer o valor real de um genótipo. Conclui-se que a população considerada apresenta condições ideais para a seleção, indicando possibilidade de obtenção de ganhos genéticos significativos. Considera-se que entre os genótipos selecionados será aproveitada a dispersão genética total (aditiva e de dominância) via processo de clonagem podendo ser esperada maximização dos ganhos genéticos. Para Maia et al. (2011) a multiplicação vegetativa, possível em algumas espécies, apresenta um fator facilitador para o melhoramento, aumentando 
significativamente as possibilidades de obtenção de ganho em eficiência do processo seletivo.

De acordo com Brown et al. (2009) métodos mais eficientes de análise e classificação de genótipos podem ser necessários, dada a complexidade de alguns caracteres de manga. Para esses autores, estimativas de herdabilidade acrescentam informações valiosas para os melhoristas de manga no estabelecimento eficiente de esquemas de cruzamentos e no processo seletivo. Nesse trabalho, níveis elevados de repetibilidade foram obtidos para as variáveis: peso do fruto, comprimento do fruto, largura do fruto, resistência a antracnose e para o atributo coloração da casca.

As estimativas dos coeficientes de correlações genéticas mensuradas entre pares de variáveis como: massa do fruto, comprimento do fruto - $\mathrm{CF}$, diâmetro maior do fruto - DMF, diâmetro menor do fruto - $\mathrm{DMeF}$, massa da casca , massa da semente , massa da polpa , porcentagem de polpa , firmeza da polpa , teor de sólidos solúveis totais (Brix), relação (sólidos solúveis totais (Brix)/Acidez) e $\mathrm{pH}$ podem ser visualizadas na Tabela 2 .

Em programas de melhoramento as estimativas de associações genéticas entre caracteres são indispensáveis, uma vez que permitem ao melhorista avaliar a resposta seletiva e obter ganhos indiretos em outras variáveis. Assim, variáveis de natureza genética complexa e bastante influenciadas pelo ambiente, podem ser selecionadas indiretamente a partir de variáveis tomadas com medidas mais fáceis e menos passíveis de erros de mensuração. As variáveis massa do fruto e massa da polpa apresentaram altas correlações genéticas com as variáveis comprimento e diâmetro maior e menor do fruto. Assim, estas podem ser tomadas para seleção das primeiras aumentando a eficiência do processo seletivo e garantindo ganhos genéticos nos atributos massa do fruto e massa da polpa que são de mensuração mais difícil. 
Tabela 2. Coeficientes de correlações genotípicas entre: massa do fruto (MF), comprimento do fruto (CF), diâmetro maior do fruto (DMF), diâmetro menor do fruto (DMeF), massa da casca (MC), massa da semente (MS), massa da polpa (MP), porcentagem de polpa (\%), firmeza da polpa (FP), teor de sólidos solúveis totais (ํix), relação teor de sólidos solúveis totais (( ${ }^{\text {Brix }) / A c i d e z) ~ e ~} \mathrm{pH}$, de genótipos de manga rosa.

\begin{tabular}{|c|c|c|c|c|c|c|c|c|c|c|c|c|}
\hline & MF & $\mathrm{CF}$ & DMF & $\mathrm{DMeF}$ & $\mathrm{MC}$ & MS & MP & $\%$ polpa & FP & ${ }^{\circ}$ Brix & $\begin{array}{l}{ }^{\circ} \text { Brix / } \\
\text { Acidez }\end{array}$ & $\mathrm{pH}$ \\
\hline MF & 1,0000 & $\mathbf{0 , 8 3 1 1}$ & $\mathbf{0 , 8 9 0 3}$ & 0,9252 & 0,8444 & 0,6118 & 0,9856 & 0,3958 & 0,2187 & $-0,0603$ & $-0,2657$ & 0,0228 \\
\hline $\mathrm{CF}$ & & 1,0000 & 0,6346 & 0,6558 & 0,7717 & 0,4457 & 0,8205 & 0,2428 & 0,1144 & $-0,1141$ & $-0,3363$ & $-0,0573$ \\
\hline DMF & & & 1,0000 & 0,9170 & 0,7336 & 0,6270 & 0,8485 & 0,2624 & 0,2678 & $-0,0495$ & $-0,2083$ & 0,0365 \\
\hline $\mathrm{DMeF}$ & & & & 1,000 & 0,6962 & 0,5978 & 0,9235 & 0,4821 & 0,3008 & $-0,1542$ & $-0,3518$ & $-0,0488$ \\
\hline $\mathrm{MC}$ & & & & & 1,0000 & 0,6165 & 0,7635 & 0,0261 & 0,0246 & $-0,0718$ & $-0,2569$ & $-0,0459$ \\
\hline MS & & & & & & 1,0000 & 0,5003 & $-0,2763$ & 0,1175 & 0,1299 & $-0,0476$ & 0,0750 \\
\hline MP & & & & & & & 1,0000 & 0,5257 & 0,2498 & $-0,0810$ & $-0,2719$ & 0,0194 \\
\hline$\%$ polpa & & & & & & & & 1,0000 & 0,3918 & $-0,541$ & $-0,2257$ & $-0,0029$ \\
\hline FP & & & & & & & & & 1,0000 & $-0,1766$ & $-0,3312$ & $-0,1232$ \\
\hline${ }^{\circ}$ Brix & & & & & & & & & & 1,0000 & 0,6564 & $\mathbf{0 , 8 1 9 7}$ \\
\hline Brix / & & & & & & & & & & & 1,0000 & 0,6082 \\
\hline Acidez & & & & & & & & & & & & \\
\hline pH & & & & & & & & & & & & 1,0000 \\
\hline
\end{tabular}

Revista Agrotecnologia, Anápolis, v. 5, n. 1, p. 01 - 16, 2014 
Correlações genéticas baixas e negativas foram observadas entre as variáveis: \% de polpa, firmeza do fruto, teor de sólidos solúveis totais (Brix), relação: sólidos solúveis totais (Brix)/Acidez e pH e as demais características incluídas no estudo excetuando-se o coeficiente entre sólidos solúveis totais ( Brix) e $\mathrm{pH}$ $(0,8239)$. Isso impossibilita a seleção indireta envolvendo aquelas variáveis. Genótipos com sólidos solúveis totais ( Brix) elevados também são aqueles que apresentam elevado $\mathrm{pH}$. Estes atributos são importantes para frutos destinados ao consumo in natura (frutos de mesa).

As predições dos valores genotípicos (componentes de médias) são apresentadas nas Tabelas 3 e 4 .

Tabela 3. Predição dos valores genotípicos: ganho genético e nova média (BLUP Individual) para as variáveis: massa do fruto, massa da polpa e \% da polpa, de genótipos de manga rosa.

\begin{tabular}{|c|c|c|c|c|c|c|c|c|}
\hline \multicolumn{9}{|c|}{ Componentes de Média (BLUP Individual) } \\
\hline \multicolumn{3}{|c|}{ Massa do Fruto } & \multicolumn{3}{|c|}{ Massa da Polpa } & \multicolumn{3}{|c|}{$\%$ Polpa } \\
\hline$\overline{\text { Genótipo }}$ & Ganho & $\begin{array}{l}\text { Nova } \\
\text { Média }\end{array}$ & $\overline{\text { Genótipo }}$ & Ganho & $\begin{array}{l}\text { Nova } \\
\text { Média }\end{array}$ & Genótipo & Ganho & $\begin{array}{l}\text { Nova } \\
\text { Média }\end{array}$ \\
\hline 15 & 306,8442 & 657,7128 & 15 & 250,6444 & 512,2945 & 15 & 4,6974 & 78,5423 \\
\hline 22 & 282,1357 & 633,0043 & 14 & 209,1509 & 470,8010 & 14 & 4,5908 & 78,4357 \\
\hline 20 & 254,4016 & 605,2703 & 22 & 187,3579 & 449,0081 & 17 & 3,9643 & 77,8092 \\
\hline 14 & 237,0902 & 587,9589 & 20 & 172,0481 & 433,6982 & 19 & 3,5923 & 77,4372 \\
\hline 18 & 209,0311 & 559,8998 & 18 & 151,3928 & 413,0429 & 25 & 3,3339 & 77,1788 \\
\hline 13 & 184,4757 & 535,3444 & 19 & 135,0863 & 396,7365 & 21 & 3,1610 & 77,0059 \\
\hline 19 & 166,6979 & 517,5665 & 17 & 122,4913 & 384,1414 & 7 & 3,0229 & 76,8678 \\
\hline 17 & 151,8876 & 502,7562 & 13 & 111,3899 & 373,0400 & 18 & 2,7839 & 76,6288 \\
\hline 9 & 136,4103 & 487,2789 & 9 & 100,1087 & 361,7588 & 9 & 2,5414 & 76,3863 \\
\hline 16 & 122,8640 & 473,7327 & 16 & 90,1498 & 351,7999 & 16 & 2,3166 & 76,1615 \\
\hline 8 & 109,3491 & 460,2177 & 8 & 80,1068 & 341,7569 & 24 & 2,1147 & 75,9596 \\
\hline 3 & 97,9262 & 448,7949 & 3 & 71,2791 & 332,9292 & 20 & 1,9391 & 75,7839 \\
\hline 1 & 87,3375 & 438,2062 & 1 & 63,4534 & 325,1035 & 26 & 1,7851 & 75,6300 \\
\hline 4 & 77,9950 & 428,8637 & 4 & 56,6844 & 318,3345 & 8 & 1,6525 & 75,4974 \\
\hline 11 & 69,6770 & 420,5457 & 24 & 49,7328 & 311,3830 & 4 & 1,5182 & 75,3631 \\
\hline 6 & 62,3848 & 413,2535 & 11 & 43,6330 & 305,2831 & 13 & 1,3844 & 75,2293 \\
\hline 23 & 54,7464 & 405,6151 & 26 & 38,0800 & 299,7301 & 1 & 1,2631 & 75,1080 \\
\hline 24 & 47,7046 & 398,5732 & 23 & 33,0436 & 294,6937 & 2 & 1,1526 & 74,9975 \\
\hline 26 & 41,1954 & 392,0640 & 6 & 28,5170 & 290,1671 & 3 & 1,0254 & 74,8703 \\
\hline 5 & 34,9154 & 385,7841 & 25 & 24,4157 & 286,0659 & 5 & 0,9036 & 74,7485 \\
\hline 2 & 29,0917 & 379,9604 & 2 & 20,3687 & 282,0188 & 23 & 0,7745 & 74,6193 \\
\hline 10 & 23,5147 & 374,3834 & 5 & 16,6552 & 278,3053 & 22 & 0,6553 & 74,5002 \\
\hline 25 & 18,4216 & 369,2902 & 10 & 12,7807 & 274,4308 & 10 & 0,5381 & 74,3830 \\
\hline 7 & 12,8826 & 363,7513 & 7 & 9,0207 & 270,6708 & 11 & 0,3645 & 74,094 \\
\hline 12 & 6,4100 & 357,2787 & 21 & 4,6824 & 266,3326 & 12 & 0,1972 & 74,0421 \\
\hline 21 & 0,0000 & 350,8687 & 12 & 0,0000 & 261,6501 & 6 & 0,0000 & 73,8449 \\
\hline
\end{tabular}


Tabela 4. Predição dos valores genotípicos: ganho genético e nova média (BLUP Individual) para as variáveis : firmeza da polpa, sólidos solúveis totais ( ${ }^{\text {Brix}) ~ e ~ r e l a c ̧ a ̃ o: ~}$ sólidos solúveis totais ( Brix)/Acidez, de genótipos de manga rosa.

\begin{tabular}{|c|c|c|c|c|c|c|c|c|}
\hline \multicolumn{9}{|c|}{ Componentes de Média (BLUP Individual) } \\
\hline \multicolumn{3}{|c|}{ Firmeza da Polpa } & \multicolumn{3}{|c|}{ sólidos solúveis totais $\left({ }^{\circ}\right.$ Brix $)$} & \multicolumn{3}{|c|}{$\begin{array}{l}\text { Relação: sólidos solúveis totais ( } \\
{ }^{\circ} \text { Brix)/Acidez }\end{array}$} \\
\hline Genótipo & Ganho & $\begin{array}{l}\text { Nova } \\
\text { Média }\end{array}$ & Genótipo & Ganho & $\begin{array}{l}\text { Nova } \\
\text { Média }\end{array}$ & Genótipo & Ganho & $\begin{array}{l}\text { Nova } \\
\text { Média }\end{array}$ \\
\hline 16 & 7,9464 & 14,3362 & 10 & 4,5601 & 20,6468 & 2 & 39,0047 & 80,1794 \\
\hline 21 & 6,6952 & 13,0849 & 11 & 4,4671 & 20,5538 & 11 & 36,2511 & 77,4258 \\
\hline 18 & 5,2232 & 11,6130 & 23 & 4,2360 & 20,3226 & 3 & 35,2063 & 76,3810 \\
\hline 17 & 4,4545 & 10,8443 & 2 & 3,8223 & 19,9090 & 7 & 33,9445 & 75,1192 \\
\hline 20 & 3,9502 & 10,3400 & 3 & 3,4737 & 19,5604 & 10 & 33,1703 & 74,3450 \\
\hline 15 & 3,4548 & 9,8446 & 18 & 3,1576 & 19,2443 & 14 & 30,1801 & 71,3548 \\
\hline 14 & 3,0362 & 9,4260 & 17 & 2,8960 & 18,9827 & 1 & 27,3955 & 68,5702 \\
\hline 4 & 2,7087 & 9,0985 & 6 & 2,6606 & 18,7473 & 9 & 24,8809 & 66,0556 \\
\hline 3 & 2,4471 & 8,8369 & 7 & 2,4751 & 18,5618 & 6 & 22,6548 & 63,8295 \\
\hline 9 & 2,2271 & 8,6168 & 1 & 2,3100 & 18,3967 & 23 & 20,7864 & 61,9611 \\
\hline 19 & 2,0470 & 8,4368 & 8 & 2,1570 & 18,2437 & 12 & 18,4132 & 59,5878 \\
\hline 22 & 1,8617 & 8,2515 & 9 & 1,9989 & 18,0855 & 21 & 16,4065 & 57,5812 \\
\hline 7 & 1,6713 & 8,0611 & 26 & 1,8554 & 17,9421 & 18 & 14,5285 & 55,7032 \\
\hline 6 & 1,5079 & 7,8976 & 24 & 1,7056 & 17,7922 & 4 & 12,8857 & 54,0604 \\
\hline 5 & 1,3648 & 7,7545 & 4 & 1,5631 & 17,6498 & 24 & 11,4505 & 52,6252 \\
\hline 24 & 1,2260 & 7,6158 & 16 & 1,4385 & 17,5252 & 19 & 10,1303 & 51,3050 \\
\hline 13 & 1,0991 & 7,4889 & 14 & 1,2710 & 17,3577 & 8 & 8,7864 & 49,9611 \\
\hline 12 & 0,9850 & 7,3747 & 22 & 1,1103 & 17,1969 & 22 & 7,5741 & 48,7488 \\
\hline 1 & 0,8565 & 7,2463 & 13 & 0,9631 & 17,0497 & 13 & 6,3227 & 47,4973 \\
\hline 8 & 0,7400 & 7,1298 & 20 & 0,8055 & 16,8922 & 20 & 5,1580 & 46,3327 \\
\hline 10 & 0,6180 & 7,0077 & 15 & 0,6600 & 16,7466 & 25 & 4,0858 & 45,2605 \\
\hline 2 & 0,5045 & 6,8943 & 25 & 0,5020 & 16,5887 & 17 & 3,0572 & 44,2319 \\
\hline 25 & 0,3962 & 6,7860 & 21 & 0,3550 & 16,4417 & 16 & 1,9816 & 43,1563 \\
\hline 26 & 0,2793 & 6,6690 & 12 & 0,1958 & 16,2824 & 15 & 0,9831 & 42,1578 \\
\hline 23 & 0,1461 & 6,5359 & 19 & 0,0000 & 16,0867 & 26 & 0,0000 & 41,1747 \\
\hline 11 & 0,0000 & 6,3898 & & & & & & \\
\hline
\end{tabular}

Os resultados mostraram que ocorreu uma alteração no ordenamento dos genótipos, como reflexo da correlação genotípica de baixa a média magnitude, exceção feita para as variáveis massa do fruto e massa da polpa e entre teor de sólidos solúveis totais (Brix) e pH.

As variáveis: massa da polpa e massa do fruto apresentaram alta correlação $\quad(0,9856)$. Para essas variáveis os genótipos que apresentaram maiores ganhos genéticos são, respectivamente, $15,14,22,20,18,19$, $17,13,9,16$ e 8 ; e $15,22,20,14,18$, 13, 19, 17, 9, 16 e 8. Como esperado, houve alto grau de concordância no ordenamento entre os genótipos nos dois grupos, refletindo aquela associação genética em alta magnitude. 
Visando a seleção precoce tomando como critério seletivo as variáveis massa da polpa e massa do fruto que refletem diretamente o potencial produtivo do material genético esses genótipos são candidatos à seleção.

Para porcentagem de polpa os genótipos que apresentaram melhor classificação foram: 15, 14, 17, 19, 25, $21,7,18,9,16$ e 24 , superando a média geral $(73,845)$. Valores $>60 \%$ para essa característica são altamente desejados para aproveitamento de derivados industriais. Com base no teor de sólidos solúveis totais (Brix), os genótipos em ordem decrescente de ganho genético são: $10,11,23,2,3,18,17,6,7,1$ e 8. Os valores superam a média geral $(16,087)$ sendo, portanto, candidatos a seleção.

Para variável firmeza da polpa, os genótipos que apresentaram maior ganho genético foram: 16, 21, 18, 17,

\section{CONCLUSÕES}

As estimativas dos coeficientes de repetibilidade altos e medianos expressaram estabilidade para as variáveis através do tempo, permitindo estimar o número de medições
20, 15, 14 e 4. Esta característica define o tempo útil de prateleira (shelf-life) dos frutos. Para Pinto et al. (2011) em mercado exigente em qualidade, a comercialização da manga fresca (in natura) parece ser bem mais complexa que seus produtos processados, em virtude de ser um produto altamente perecível.

A relação sólidos solúveis totais ( Brix)/Acidez é um indicativo do sabor do fruto assim valores elevados para essa relação são atribuídos a frutos de melhor qualidade. Os genótipos que apresentaram os maiores ganhos genéticos para essa característica são em ordem decrescente: $2,11,3,7,10,14,1$ e 9 .

necessárias para predizer o valor real de um genótipo.

As variáveis massa do fruto e massa da polpa apresentaram altas correlações genéticas com as variáveis comprimento e diâmetro do fruto, estas podem ser tomadas para seleção indireta 
dos atributos de massa que são de mensuração mais passíveis de erros de mensuração.

Ocorreu uma alteração no ordenamento dos genótipos entre variáveis como reflexo da correlação genotípica de baixa a média magnitude , exceto para as variáveis massa do fruto

\section{REFERÊNCIAS}

ALVES, R. M.; RESENDE, M. D. V. Avaliação genética de indivíduos e progênies de cupuaçuzeiro no estado do Pará e estimativas de parâmetros genéticos. Revista Brasileira de Fruticultura, v. 30, n. 6, p. 696-701, 2008.

BROWN, J. S.; SCHNELL, R. J.; AVALA-SILVA，T.; MOORE，J. M.; TONDO, C. L.; WINTERSTEIN, M. C. Broad-sense Heritability Estimates for Fruit Color and Morphological Traits from Open-pollinated Half-sib Mango Families. Hortscience. v. 44, n.3, p. 1552-1556. 2009.

CARGNELUTTI-FILHO, A.; STORCK, L. Measures of experimental precision degree in corn cultivar competition trials. Pesquisa Agropecuária Brasileira, v. 44, n.2, p. 111-117, 2009. e massa da polpa e entre sólidos solúveis totais ( Brix) e pH.

Esse estudo permitiu obter informações técnicas para a realização de uma seleção precoce, na cultura da mangueira, com base nas características agroindustriais.

HARDNER, C. M.; BALLY, I.S.E; WRIGHT, C.L. Prediction of breeding values for average fruit weight in mango using a multivariate individual mixed model. Euphytica, v. 186, n. 2, p. 463-477, 2012.

LAVI, U; TOMER, E; GAZIT, S. Inheritance of agriculturally important traits in mango. Euphytica. v. 44, n.2, p. 5-10, 1989.

LAVI, U; TOMER, E; GAZIT, S; HILLEL J. Components of the genetic variance and genetic correlations between traits in Mango. Scientia Horticulturae. v. 75, n.2, p. 11-25, 1998.

MAIA, M. C. C.; RESENDE, M. D. V.; OLIVEIRA, L. C.; ALVES, R.M.; SILVA FILHO, J. L.; ROCHA, M. M.; CAVALCANTE, J. J. $\quad$ V.; RONCATTO, G. Análise genética de famílias de meios-irmãos de 
cupuaçuzeiro. Pesquisa Florestal RESENDE, M. D. V.; DIAS, L. A. S. Brasileira. v. 31, n. 66. p.123-130, Aplicação da metodologia de modelos 2011. mistos (REML/BLUP) na estimação de PINTO, A. C. Q.; LIMA NETO, F. P.; parâmetros genéticos e predição de GUIMARÃES, T. G. Estratégias do valores genéticos aditivos e genotípicos melhoramento genético da manga em espécies frutíferas. Revista visando atender a dinâmica de mercado. Brasileira de Fruticultura. v. 1, n.11, Revista Brasileira de Fruticultura. v. p. 44-52, 2000.

33, n. Especial, p. 64-72, 2011. 